\title{
Failure simulation of connecting rods without pistons using finite element method
}

\author{
Andoko ${ }^{1, *}$ and Nanang Eko Saputro ${ }^{1}$ \\ ${ }^{1}$ Department of Mechanical Engineering, Engineering Faculty, Universitas Negeri Malang, 65145 \\ Malang, Indonesia
}

\begin{abstract}
The combustion of fuel takes place inside the cylinder with the oxygen of the air, producing a very high-pressure combustion gas. The combustion gas does work on the piston and then passes through the connecting rod to the crankshaft. The reciprocating translational motion of the piston may damage the connecting rod. A simulation using ANSYS was performed on each of the three connecting rod materials. Results showed that the maximum deformation occurred in the connecting rod made of structural steel, aluminium alloy, and titanium alloy was 0.239 $\mathrm{mm}, 0.672 \mathrm{~mm}$, and $0.496 \mathrm{~mm}$, respectively.
\end{abstract}

\section{Introduction}

Piston utilises one or more cylinders in which the reciprocating translational motion of the piston is converted to rotational motion by the crankshaft. The combustion of fuel takes place inside the cylinder with the oxygen of the air, producing a very high-pressure combustion gas. The combustion gas does work on the piston and then passes through the connecting rod to the crankshaft. The reciprocating translational motion of the piston results in rotational motion at the crankshaft and vice versa, the rotation of the crankshaft causes the translational motion of the piston [1].

The reciprocating motion of the piston may damage the connecting rod [2][3]. The damage leads to a decrease in petrol engine efficiency. A connecting rod should be strong enough to withstand high pressures but light enough to reduce inertia forces. Proper selection of materials is thus necessary to produce fully functioning connecting rods [4]. Materials commonly used for making connecting rods are structural steel, aluminium alloy, and titanium alloy [4]. The damage analysis was performed using finite element method with ANSYS Workbench 15 [5], and the connecting rod was designed using CAD software called Autodesk Inventor 2014.

\section{Literature Review}

\subsection{Connecting Rods}

A connecting rod is a rod subjected to complex loading states. It can withstand high cyclic loads of $10^{5}$ to $10^{9}$ cycles, including high compressive loads due to combustion and high

\footnotetext{
*Corresponding author: andoko.ft@um.ac.id
} 
tensile loads due to inertial forces [6]. Therefore, the durability of the components is essential.

\subsection{Connecting rod components}

The end of the connecting rod connected to the piston pin is termed as the small end, while the one attached to the crankshaft is called the big end. Crankshaft rotating at high speed inside the big end causes a rise in temperature. The use of metal in the big end is particularly important to avoid that condition. The metal is lubricated with oil, and some of the oil is sprinkled from the oil hole to the inside of the piston to cool the plunger or piston. Along with the crank, this system forms a simple mechanism that converts linear motion into circular motion.

\subsection{Connecting rod damage}

Figure 1 shows one type of connecting rod failure. Deformation occurred to the piston, making it bent. This damage resulted in a significant decrease in the performance of the connecting rod.

Fig. 1. Connecting rod damage

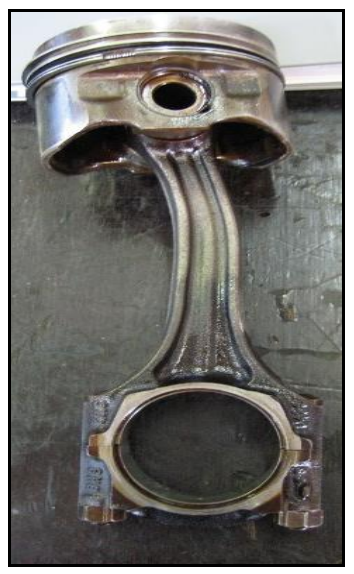

\section{Processing and Method}

A connecting rod is made of a wide range of materials; those commonly used in automotive connecting rods are Ti alloy, Al alloy, and steel.

\subsection{Connecting road design}

Figure 3 shows the dimensions of the connecting rod created using Autodesk Inventor. 

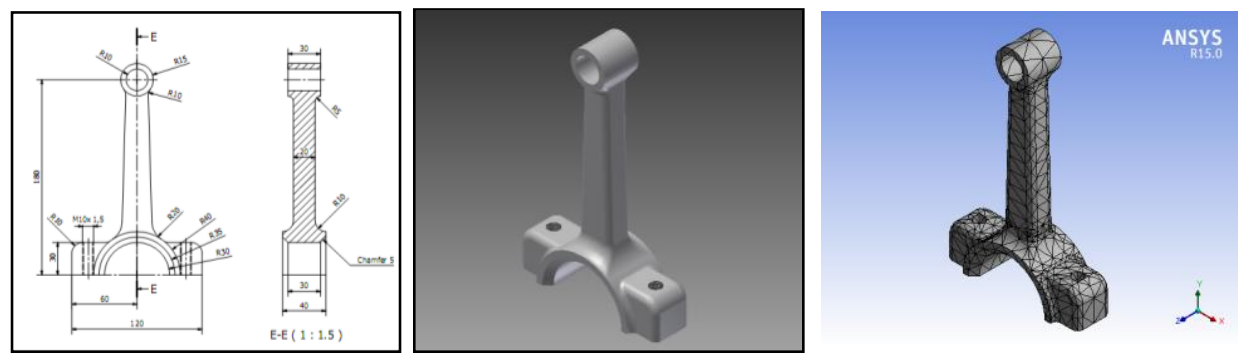

Fig. 2. Connecting rod model

\subsection{ANSYS simulation}

Each connecting piston was analysed using ANSYS Workbench 15 for various measures, i.e. stress, deformation, and safety factor. Figure 4 shows the meshing of connecting rod, generating a model with 5686 nodes and 3069 elements.

\section{Result and Discussion}

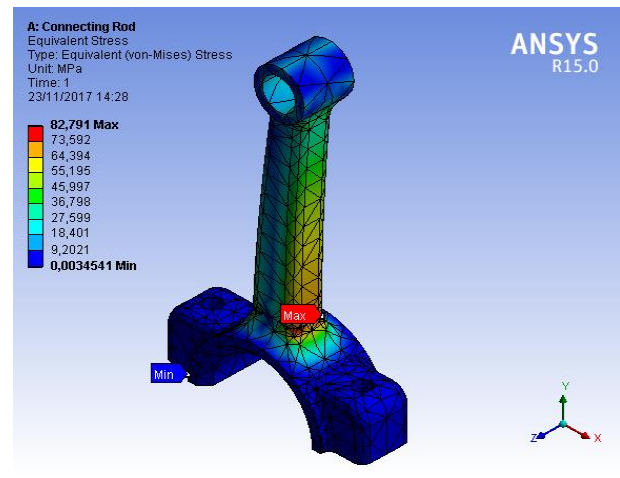

(a)

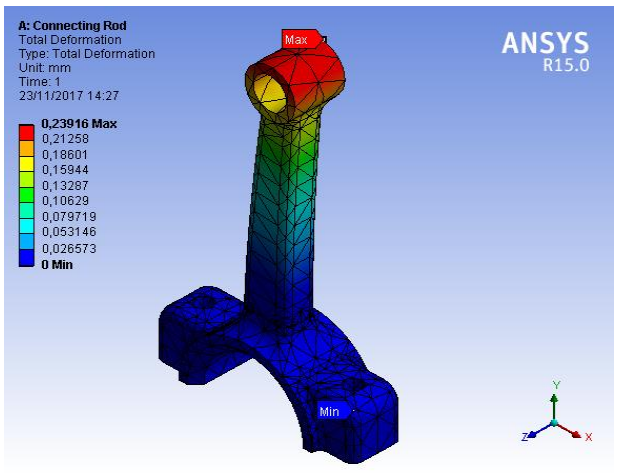

(b)

Fig. 3. (a) equivalent stress and (b) total deformation (structural steel)

As shown in Figure 3a, the connecting rod made of structural steel subjected to a force of $5000 \mathrm{~N}$ had maximum stress of $82.791 \mathrm{MPa}$ and minimum stress of $0.0034541 \mathrm{MPa}$. The total deformation occurring this connecting rod was $0.23916 \mathrm{~mm}$ (see Figure $3 \mathrm{~b}$ ). 


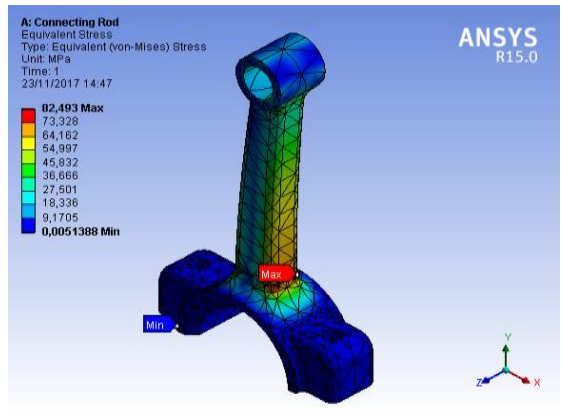

(a)

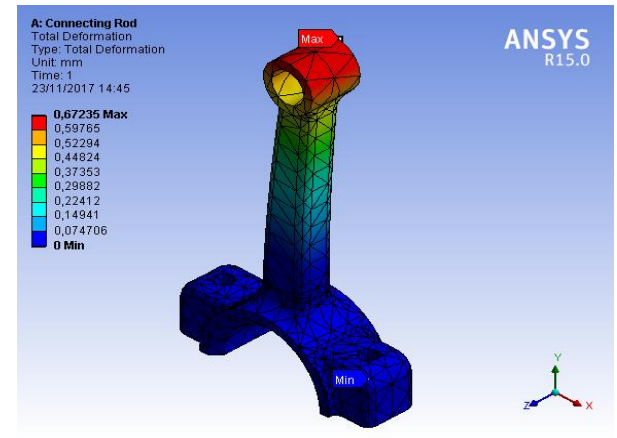

(b)

Fig. 4. (a) equivalent stress and (b) total deformation (aluminium alloy)

The connecting rod made of aluminium alloy subjected to a force of $5000 \mathrm{~N}$ had maximum stress of $82.493 \mathrm{MPa}$ and minimum stress of $0.0051388 \mathrm{MPa}$ (see Figure 4a). The total deformation occurring in this connecting rod was $0.67235 \mathrm{~mm}$ (see Figure $4 \mathrm{~b}$ ).

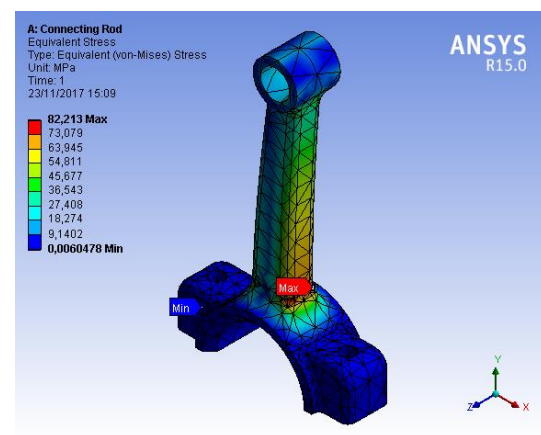

(a)

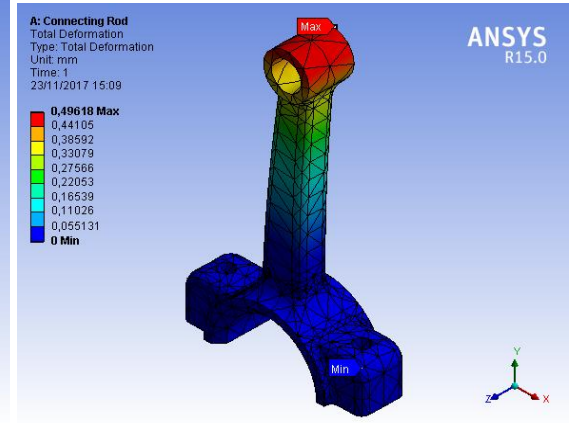

(b)

Fig. 5. (a) equivalent stress and (b) total deformation (titanium alloy)

The connecting rod made of titanium alloy subjected to a force of $5000 \mathrm{~N}$ had maximum stress of $82.213 \mathrm{MPa}$ and minimum stress of $0.0060478 \mathrm{MPa}$ (see Figure $5 \mathrm{a}$ ). The total deformation occurring this connecting rod was $0.49618 \mathrm{~mm}$ (see Figure $5 \mathrm{~b}$ ).

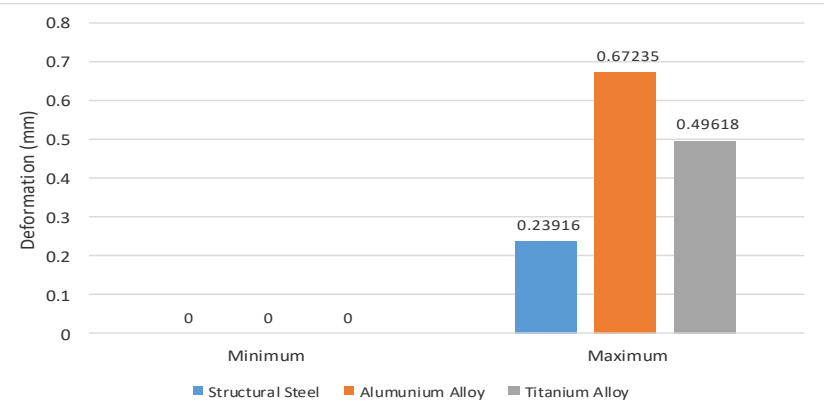

Fig. 6. Comparison of the connecting rod deformation of the three materials 
Among the other two connecting rods, the one made of aluminium alloy had the highest maximum deformation, i.e. $0.67235 \mathrm{~mm}$. However, the connecting rod made of structural steel had the lowest maximum deformation, i.e. $0.23916 \mathrm{~mm}$ (see Figure 6).

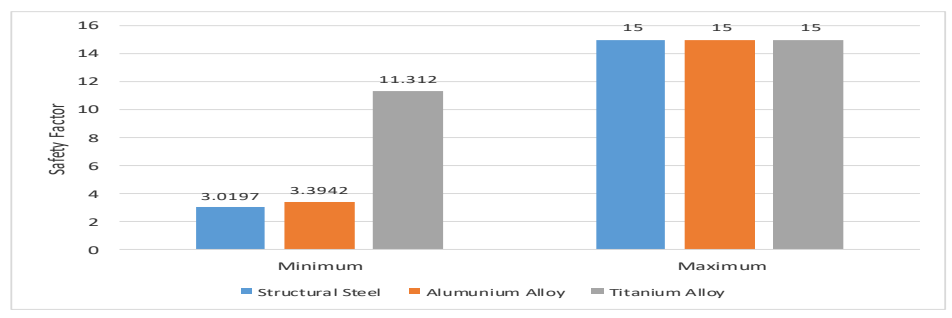

Fig. 7. Comparison of the safety factor of the three connecting rod materials

\section{Conclusion}

Among the other connecting rods made of aluminium alloy and titanium alloy, the one made of structural steel had the highest maximum stress of $82.791 \mathrm{MPa}$. The connecting rod made of aluminium alloy had the highest maximum deformation of $0.67235 \mathrm{~mm}$. The maximum safety factor of the three connecting rods was the same, i.e. 15.

The authors acknowledge to State University of Malang for Hibah Penelitian PNBP UM 2018 with contract number 2.3.144/UN32.14/LT/2018.

\section{References}

1. Wjayanti, F., dan Irwan, D. Jurnal Ilmiah Teknik Mesin, 2 (1): 34-42. (2014)

2. G. Khare, S., Singh, O. P., Dora, K. B., dan Sasun, C. Engineering Failure Analysis, 19,77-86 (2012)

3. He, B., Shi, G., Sun, J., Chen, S., dan Nie, R. C Engineering Failure Analysis, 34, 443450 (2013)

4. Nandish B., Muthanna K. P., Kaveriappa, M. B. Applied Mechanics and Materials, 867, 228-232 (2016)

5. Andrei, M. M., Gheorge, N., Lonut, R. M., Mihai, B., dan Lulian, H. L. Applied Mechanics and Materials, 657, 725-729 (2014)

6. Ali, M. M., dan Haneef, M. 2015. 4th International Conference on Materials Processing and Characterization, 2, 2094 (2013) 